\title{
FAKTOR-FAKTOR YANG MEMPENGARUHI IMPLEMENTASI PROGRAM INDONESIA SEHAT DENGAN PENDEKATAN KELUARGA (PIS-PK) DI PUSKESMAS KABUPATEN POLEWALI MANDAR
}

\section{FACTORS THAT AFFECT THE IMPLEMENTATION OF HEALTHY INDONESIA PROGRAM THROUGH FAMILY APPROACH (PIS-PK) IN HEALTH CENTERS OF POLEWALI MANDAR REGENCY}

\author{
Kuntum Hartomo Pujosiswanto ${ }^{1}$, Sukri Palutturi ${ }^{2}$, Hasanuddin Ishak ${ }^{3}$ \\ ${ }^{1}$ Program Pascasarja,Departemen administrasi Kebijakan Kesehatan, Fakultas Kesehatan \\ Masyarakat, Universitas Hasanuddin \\ ${ }^{2}$ Departemen administrasi Kebijakan Kesehatan, Fakultas Kesehatan Masyarakat, \\ Universitas Hasanuddin \\ ${ }^{3}$ Departemen Kesehatan Lingkungan, Fakultas Keehatan Masyarakat, Universitas Hasanuddin \\ Email Korespondensi: pru.kuntum@gmail.com)
}

\begin{abstract}
ABSTRAK
Kebijakan penguatan upaya kesehatan dasar yang berkualitas salah satunya dilakukan melalui Program Indonesia Sehat dengan Pendekatan Keluarga (PIS-PK), monitoring dan evaluasi kebijakan diperlukan untuk mengukur apakah implementasi kebijakan berjalan sesuai dengan tujuan yang diharapkan. Tujuan penelitian ini adalah untuk mengetahui mengenai faktor-faktor yang mempengaruhi implementasi Program Indonesia Sehat dengan Pendekatan Keluarga (PIS-PK) di Puskesmas Kabupaten Polewali Mandar. Penelitian ini menggunakan desain kualitatif, penentuan informan dengan teknik purposive sampling dimana informan utama sebanyak lima orang dan informan triangulasi sebanyak enam orang. Analisis data menggunakan content analysis. Hasil penelitian didapatkan bahwa implementasi PIS-PK sudah terlaksana namun belum maksimal. Faktor yang mendukung implementasi adalah dari faktor komunikasi sudah berjalan dengan baik dengan adanya sosialisasi baik internal maupun eksternal, faktor sikap pelaksana memiliki komitmen mendukung terlaksananya program dengan baik. Sedangkan faktor yang menghambat dari sisi sumberdaya adalah keterbatasan sarana prasarana program dan keterlambatan pencairan anggaran. Dari faktor struktur birokrasi belum terbentuknya kordinasi berjenjang antar dinas kesehatan dan puskesmas. Saran agar dinas kesehatan kabupaten dapat segera membuat struktur organisasi program untuk mempermudah koordinasi, memudahkan proses pencairan anggaran serta mengadakan sarana-prasarana pendukung program.
\end{abstract}

Kata Kunci : Implementasi kebijakan, PIS-PK, pendekatan keluarga

\begin{abstract}
Policies to strengthen basic health efforts one of which is by conducting the Healthy Indonesia Program through Family Approach (PIS-PK), monitoring and evaluation of the policy is needed to measure whether the implementation of the policy run in accordance with the intended purpose. The purpose of this research is to know about the factors that influence the implementation of Healthy Indonesia Program through Family Approach (PIS$P K)$ in Puskesmas Polewali Mandar District. This research uses qualitative design, informant in this study using purposive sampling technique with five main informants and six people of informant triangulation, data analysis using content analysis. The result of the research shows that the implementation of PIS-PK has been implemented but not yet maximal. Factors that support the implementation is communication factor already running well with the internal and external socialization, from the dispotition side the implementor has a commitment to support the implementation of the program well. While the inhibiting factors from the resource side are the limited facilities of the program infrastructure and the delayed disbursement of the budget. from bureaucracy structure factor has not yet established tiered coordination between the health offices and puskesmas. We recommend that the district health office can immediately create the organizational structure of the program to facilitate coordination, ease the process of disbursement of the budget as well as holding facilities supporting the program.
\end{abstract}

Keywords: Policy Implementation, PIS-PK, Family Approach 
PENDAHULUAN

Dalam deklarasi Alma Ata ditetapkan bahwa kesehatan adalah hak asasi bagi setiap manusia, setiap manusia berhak mendapatkan pelayanan kesehatan yang terjangkau, dan berkualitas. Aksesibilitas masyarakat terhadap pelayanan kesehatan dipengaruhi oleh banyak hal yang sangat multidimensional. Aksesibilitas tidak hanya dipengaruhi oleh faktor supply semacam ketersediaan tenaga kesehatan dan fasilitas, tetapi juga dipengaruhi oleh beberapa hal yang justru bisa menjadi hambatan bila tidak dikelola dan diantisipasi dengan baik. Misalnya, kondisi geografis dan cakupan kepemilikan jaminan kesehatan (Laksono et al., 2016).

Selain masalah aksesibilitas sampai saat ini kondisi kesehatan masyarakat di Indonesia masih memprihatinkan, meskipun beberapa indikator menunjukkan perbaikan namun masih jauh dari target yang ditetapkan bersama dalam Suistenable Development Goals (SDGs). Dari hasil Riset Kesehatan Dasar (Riskesdas) tahun 2013 ditemukan beberapa prevalensi penyakit dan faktor risikonya semakin meningkat. Masalah stunting (anak balita pendek), sampai saat ini masih belum terselesaikan, walaupun data SDKI menunjukkan bahwa angka kematian ibu pada periode tahun 1994 (390 per 100.000 kelahiran hidup) sampai dengan tahun 2007 (228 per 100.000 kelahiran hidup) mengalami penurunan, akan tetapi pada tahun 2012 meningkat kembali menjadi sebesar 359 dan pada tahun 2015 menurun menjadi 305 per 100.000 kelahiran hidup. Untuk AKB dapat dikatakan terus menurun, pada 2012 menunjukan angka 32/1.000 KH (SDKI 2012), dan pada tahun 2015 sebesar 22,23 per 1.000 kelahiran hidup (Direktorat Kesehatan Keluarga Kementerian Kesehatan, 2016).

Program Indonesia Sehat Dengan Pendekatan Keluarga (PIS-PK) bertujuan untuk meningkatkan akses keluarga berserta anggotanya terhadap pelayanan kesehatan yang komprehensif, meliputi pelayanan promotif dan preventif serta pelayanan kuratif dan rehabilitatif dasar Kementrian Kesehatan (2016). Pendekatan keluarga telah menjadi salah satu pendekatan yang telah dilaksanakan dibeberapa Negara berdasarkan hasil penelitian Siddharudha Shivalli (2015) menemukan bahwa pendekatan perawatan keluarga telah meningkatkan presepsi dan praktik masyarakat terhadap kesehatan dan isu-isu terkait, sedangkan di Brazil hasil penelitian menunjukkan bahwa ditemukan efek yang konsisten dari program kesehatan keluarga pada penurunan angka kematian sepanjang distribusi usia, terutama pada usia dini. Bukti menunjukkan bahwa Program 
Kesehatan Keluarga adalah alat yang sangat hemat biaya untuk meningkatkan derajat kesehatan di daerah miskin (Rocha \& Soares, 2010).

Beberapa lokasi telah melakukan pendataan meskipun dengan keterbatasan sumber daya. Salah satu penyebab belum dilakukannya pendataan di kabupaten Lebak, karena adanya kendala anggaran (Laelasari dkk., 2017). Berdasarkan hasil pendataan Propinsi Sulawesi Barat Menurut data nasional jumlah keluarga yang telah terdata per Desember 2017 sebanyak 3.928.651 keluarga atau baru sekitar 5,897\% secara nasional. Untuk wilayah Polewali Mandar sendiri, sebanyak 9794 keluarga telah didata, baru sekitar 3,329\% sampai dengan minggu pertama Desember 2017 berdasarkan data Nasional laporan website PIS-PK jumlah keluarga yang telah dikunjungi untuk wilayah puskesmas Massenga sebagai lokus jumlah keluarga yang telah didata baru sebanyak 815 keluarga dari 5.429 atau baru sekitar 0,838 \%.

Sebagai sebuah kebijakan publik Program Indonesia Sehat dengan Pendekatan Keluarga (PIS-PK) akan melewati siklus kebijakan mulai dari pembuatan kebijakan, implementasi kebijakan, dan monitoring serta evaluasi sebagai dasar pengajuan rekomendasi sebagai umpan balik (feedback) untuk pengembangan kebijakan berikutnya (Ayuningtyas, 2015).

Tujuan penilitian ini adalah peneliti tertarik untuk meneliti mengenai faktorfaktor yang mempengaruhi implementasi program Indonesia Sehat dengan Pendekatan Keluarga di Puskesmas Kabupaten Polewali Mandar.

\section{BAHAN DAN METODE}

\section{Lokasi dan Desain Penelitian:}

Penelitian ini merupakan jenis penelitian kualitatif. Penelitian ini dilaksanakan pada rentan waktu Maret-April 2018 di Kabupaten Polewali Mandar, dengan memilih 3 (tiga) puskesmas berdasarkan kategori kewilayahan yaitu Puskesmas Massenga (perkotaan), Puskesmas Pambusuang (pesisir) dan Puskesmas Tubbi Taramanu (terpencil).

\section{Pengambilan sampel}

Sampel dalam penelitian ini menggunakan teknik purposive sampling. Dimana informan utama adalah Kepala Dinas Kesehatan Kabupaten Polewali Mandar, Kordinator Tim pengelola PIS-PK Kabupaten Polewali Mandar, Kepala Puskesmas Massenga, Kepala Puskesmas Tinambung, Kepala Puskesmas Tubbi Taramanu, sedangkan informan triangulasi adalah Koordinator dan Anggota Tim PIS-PK Puskesmas Massenga, Tinambung dan Tubbi 
Taramanu Kabupaten Polewali Mandar.

\section{Metode Pengumpulan Data}

Metode dalam peneltian ini akan lebih menekankan pada metode kualitatif, didapatkan dengan mengumpulkan data melalui teknik wawancara mendalam (Indepth Interview) terhadap informan dan telaah dokumen.

\section{Analisis data}

Analisis data digunakan teknik analisis isi (content analysis) melalui tahapan reduksi data, penyajian data dan penarikan kesimpulan. Data diproses dengan menggunakan komputer dan tape recorder, data kemudian ditranskrip kedalam transkrip wawancara kemudian data disederhanakan dan dimasukkan kedalam matriks berdasarkan pada item pertanyaan kemudian dilakukan teknik analisis konten, kesimpulan dari matriks kemudian dianalisis dan dijelaskan kedalam narasi.

\section{HASIL PENELITIAN}

Implementasi Program Indonesia Sehat dengan Pendekatan Keluarga di Puskesmas Kabupaten Polewali Mandar

Implementasi Program PIS-PK di Puskesmas Kabupaten Polewali Mandar telah mulai dilaksanakan pada tahun 2017 dimana telah dilakukan sosialisasi di tingkat kabupaten mengenai tujuan dari program ini dengan melibatkan semua puskesmas dan lintas sektor terkait di tingkat kabupaten, juga pada tahun 2017 telah dilaksanakan pelatihan mengenai pelaksanaan PIS-PK bagi 20 puskesmas yang ada di wilayah kabupaten Polewali Mandar hal ini sesuai dengan yang dinyatakan informan:

“...program PIS-PK sendiri dikabupaten Polman sudah berjalan sejak awal 2017, ditahap awal sudah dilakukan sosialisasi baik internal maupun eksternal melibatkan lintas sektor dan pusksesmas telah diikutkan pelatihan di BBPK Makassar sama yang dilaksanakan propinsi yah, tapi terakhir sетиа 20 puskesmas sudah ikut pelatihan PIS-PK..." (ASN 54)

Namun sampai dengan tahun 2018 triwulan pertama dalam hal pelaksanaan program dari ketiga puskesmas yang diteliti masih dalam tahap pendataan, pada tahun 2017 hanya puskesmas Massenga yang ditunjuk sebagai lokus PIS-PK dan telah mengadakan pendataan keluarga, serta telah melakukan penginputan data pada sistem aplikasi keluarga sehat. Dari ketiga puskesmas yang diteliti menurut analisis dokumen ditemukan masih ada satu puskesmas yang sama sekali belum memasukkan hasil pendataan pada aplikasi yaitu puskesmas Tubbi Taramanu hal ini terkendala karena hanya puskesmas Tubbi Taramanu yang belum terdaftar pada aplikasi keluarga sehat, jumlah keluarga yang telah didata sampai dengan bulan april 2018 untuk kabupaten Polewali Mandar sebanyak 25.405 
KK, baru sekitar 26,4\% dari total sasaran KK

di Kabupaten Polewali Mandar sebanyak 95.884 KK, Hal ini sesuai dengan pernyataan informan

“...sampai bulan maret semua puskesmas masih mendata keluarga, tahun lalu memang sudah ada selesai satu dusun tapi belum maksimal, tahun ini kita baru fokus, lambat memang tapi yah kita tetap jalan..."(IDM 43 Tahun)

Berdasarkan pernyataan diatas kita dapat simpulkan bahwa program ini telah dilaksanakan namun belum berjalan maksimal. Sosialisasi dan pelatihan telah dilakukan di tingkat kabupaten dan dalam tahapan implementasi PIS-PK keseluruhan puskesmas kabupaten Polewali Mandar masih dalam tahapan awal yaitu kegiatan kunjungan rumah untuk pengumpulan data kesehatan keluarga.

\section{Faktor-faktor yang mempengaruhi implementasi kebijakan PIS-PK}

\section{Faktor Komunikasi}

Dari hasil penelitian diperoleh informasi bahwa dalam hal konsistensi komunikasi informasi dari tingkat kabupaten ke puskesmas sudah berjalan sesuai dengan petunjuk kebijakan yang dikeluarkan oleh kementrian kesehatan, sosialisasi baik internal maupun eksternal telah dilaksanakan baik oleh dinas kesehatan kabupaten maupun oleh puskesmas, dari ketiga puskesmas hanya puskesmas Tubbi Taramanu yang belum melaksanakan sosialisasi di tingkat eksternal hal ini sesuai dengan yang disampaikan informan:

“...iya sosialisasi sudah untuk internal sudah, kalo eksternal pada waktu kita mau mendata saja pengumuman di mesjid saja secara formal belum ada..."(MYN 32 Tahun).

“...tujuan kebijakannya untuk tahap awal ini melalui pendataan keluarga untuk memperoleh data kesehatan keluarga, dianalisis, di tentukan prioritas masalah dan tindakan untuk menengani permasalahan disuatu wilayah dalam rangka penguatan manajemen pelayanan kesehatan.. "(YSN 48 Tahun)

Sedangkan dari segi konsistensi komunikasi ditemukan bahwa :

“...Konsitensi kebijakan saya rasa iya, dari tahun lalu kami sosialisasikan tidak ada yang berubah, materinya tetap sama..." (NSM 41 Tahun)

Berdasarkan pernyataan informan diatas dari sisi komunikasi telah dilaksanakan sosialisasi program. Dari penjelasan informan keseluruhan implementor telah memahami maksud dan tujuan dari program ini ialah dalam rangka penguatan manajemen upaya pelayanan kesehatan. Sedangkan untuk konsistensi kebijakan sendiri dari hasil penelitian ditemukan bahwa kebijakan sudah berjalan dengan konsisten tidak ada perubahan atau penambahan aturan-aturan baru mengenai pelaksanaan program ini sampai penelitian ini berlangsung.

\section{Faktor Sumber daya}

Sumberdaya adalah salah satu faktor penting dalam implementasi program baik 
dari segi kecukupan maupun dari segi kualitas sumberdaya, dari hasil penelitian untuk sumberdaya anggaran dari hasil wawancara dengan informan mengemukakan informasi bahwa:

“ ...Tahun 2017 kami melakukan pendataan, di POA tidak ada khusus anggaran, karena belum jelas di juknis BOK, baru tahun ini (2018) jelas dicantumkan item kegiatan PIS-PK di dana BOK..."(AZS 42 Tahun)

“...yang 2017 itu ada anggaran penggandaan format saja sekitar 5 jutaan operasional belum ada, tahun 2018 ini karena juknis BOK sudah ada item program PIS-PK, kami di POA puskesmas menganggarkan 100 juta untuk kegiatan BOK selama setahun mulai dari pendataan sampai tahap intervensi, tapi sampai bulan empat dana BOK Belum cair, kami pakai dana pribadi saja dulu..." (YSN 48 Tahun)

Dari segi sumber anggaran dari hasil penelitian ditemukan dukungan anggaran selama tahun 2017 belum maksimal, baru pada tahun 2108 dilaksanakan perencanaan penganggaran dalam melaksanakan program PIS-PK namun dalam pencairannya masih dinilai lambat oleh informan diketiga puskesmas, sampai dengan triwulan pertama dana kegiatan belum dapat dicairkan sedangkan dinas kesehatan memasang target total coverage pada bulan juni 2018 . Sedangkan dari sisi sumberdaya sarana prasarana juga masih dirasakan kurang mendukung dalam pelaksanaan program, dari hasil penelitian ditemukan bahwa untuk pengadaan sarana pendukung dalam mengelola data keluarga seperti laptop, handphone android masih belum ada jadi petugas masih memanfaatkan sarana yang ada dipuskesmas berupa manual yaitu melalui formulir kesehatan keluarga, sedangkan untuk puskesmas Tubbi Taramanu bahkan sama sekali belum melakukan penginputan data kelurga, salah satu yang menjadi kendala adalah tidak tersedianya jaringan internet yang menjangkau wilayah puskesmas, juga terkendala data dipusat dimana puskesmas Tubbi Taramanu belum terdata didalam database Kementrian Kesehatan berikut kutipan informasi yang diperoleh dari informan:

“...kami sudah mendata, tapi hasilnya belum bisa terinput karena puskesmas kita belum terdaftar didatabase kementrian, belum lagi jaringan telpon belum sampai ke puskesmas kami, jadi agak lama dalam input ke sistem..." (SDM 42 Tahun)

Mengenai dukungan sarana prasarana program informan menyampaikan bahwa:

"kalau pengadaan Komputer,Laptop atau HP smarthphone khusus program ini belum ada, semua masih memakai pribadi,alat tensi juga biasaya kita pakai bergantian tidak ada pengadaan khusus dari dinas atau puskesmas, Pengadaan Pinkesga juga belum ada sampai saat ini..." (DM 33 Tahun)

Dari faktor sumberdaya dapat disimpulkan menjadi salah satu faktor penghambat dalam pelaksanaan kegiatan PIS-PK, ditahun 2017 anggaran untuk 
program ini masih terbatas, dan yang menjadi kendala adalah lambatnya proses pencairan anggaran yang sampai triwulan pertama petugas belum menerima dana kegiatan pendataan keluarga sedangkan mereka dituntut oleh dinas kesehatan kabupaten untuk total coverage pada juni tahun 2018, sedangkan dari sisi sarana prasarana pendukung masih dirasakan kurang mendukung pelaksanaan program, seperti aplikasi program yang belum memasukkan semua puskesmas serta belum munculnya indikator keluarga di tingkat desa sampai kabupaten, kendala jaringan internet diwilayah puskesmas terpencil, serta kurangnya sarana pendukung pengolahan data keluarga.

\section{Faktor Disposisi}

Komitmen pelaksana program PISPK sudah sangat baik, hal ini terlihat dari kuatnya keinginan dan semangat mereka dalam menjalankan program ini dari jajaran pengambil kebijakan sampai dengan pelaksana kegiatan. Hal ini sesuai dengan pernyataan informan:

“...sikap teman-teman menerimaji program ini, buktinya meskipun dana belum cair, mereka tetap semangat menjalankan program ini, jadi mereka mendata diluar jam kantor, bahkan ada yang mendata sampai magrib” (AZS, 41 Tahun)

“...sikap kami jelas menerima program ini, apalagi ini sangat membantu dalam penguatan database puskesmas, sehingga nanti intervensi bisa tepat sasaran, mungkin yang masih jadi sedikit kendala masih ada sikap sebahagian masyarakat yang menolak untuk diperiksa dan didata, tapi kami tetap upaya persuasif kemasyarakat...." (IDM43 Tahun)

Dalam pelaksanaan kebijakan PIS-PK implementor telah menunjukkan sikap menerima pelaksanaan kebijakan mereka telah menerima pelatihan dan sosialisai mengenai kegiatan PIS-PK hal ini dibuktikan dari hasil wawancara pada implementor ditiga puskesmas menyatakan mereka siap menjalankan program, implementor tetap menjalankan tahap awal kunjungan rumah untuk pendataan meskipun dengan segala keterbatasan anggaran yang mereka memiliki, dari segi sikap yang masih menjadi sedikit kendala adalah sikap penerimaan sebahagian masyarakat yang menolak untuk diperiksa dan didata oleh tenaga kesehatan.

\section{Faktor Struktur birokrasi}

Mengenai pernyataan tentang struktur birokrasi dalam hal ini koordinasi berjenjang ditemukan bahwa belum berjalan dengan baik hal ini sesuai dengan pernyataan informan:

“ kami belum pernah melakukan evaluasi triwulan pertama ini, kami belum bisa jalan maksimal, karena SK dari kepala dinas belum ditandatangi, hanya saja setahu kami yang ditunjuk sebagai pengelola dikabupaten itu dari bidang pelayanan dan perencanaan” NSM (41 Tahun)

Dalam hal koordinasi berjenjang 
Pujosiswanto , 2020

ditemukan bahwa belum terbentuknya struktur yang baku ditingkat dinas kesehatan dalam hal struktur koordinasi program dengan puskesmas, dari ketiga puskesmas meyatakan koordinasi menjadi salah satu kendala yang menghambat pelaksanaan program dilapangan, karena masalah yang ditemui tidak dapat langsung direspon oleh yang memiliki wewenang lebih tinggi dalam hal ini dinas kesehatan kabupaten dan dari ketiga puskesmas dalam hal struktur organsiasi program PIS-PK hanya puskesmas Tinambung yang telah memiliki SK pengelola program, sedangkan untuk puskesmas Massenga dan puskesmas Tubbi Taramanu mengenai tugas dan fungsi mereka dalam tim PIS-PK masih sebatas pernyataan lisan dari kepala puskesmas, tidak ditemukan bentuk fisik dalam bentuk surat keputusan.

\section{PEMBAHASAN}

Penelitian ini menemukan bahwa Implementasi Program Indonesia Sehat dengan Pendekatan keluarga (PIS-PK) telah terlaksana namun belum berjalan maksimal. Faktor-faktor yang mempengaruhi implementasi Program Indonesia Sehat dengan Pendekatan Keluarga (PIS-PK) di Puskesmas kabupaten Polewali Mandar ditemukan bahwa faktor yang mendukung yaitu faktor komunikasi sudah terlaksana dengan baik dengan adanya sosialisasi baik internal maupun eksternal puskesmas, berikutnya adalah faktor disposisi sikap pelaksana telah menerima untuk melaksanakan program, sedangkan faktor yang menghambat pelaksanaan PIS-PK adalah dari sisi faktor sumberdaya dimana masih ada keterbatasan angggaran dan keterlambatan pencairan anggaran, begitupula dengan keterbatasan sarana dan prasarana program yang masih kurang, adapun faktor struktur birokrasi belum terbentuk dengan baik sehingga koordinasi program antara puskesmas dan dinas kesehatan belum berjalan dengan baik

Untuk menjamin implementasi program dapat berjalan lancar sebelum penyampaian berbagai keluaran kebijakan dilakukan kepada kelompok sasaran maka perlu didahului dengan penyampaian informasi, dalam hal ini berdasarkan hasil penelitian dilapangan transmisi komunikasi kebijakan program telah berjalan dengan baik yang dilakukan berupa kegiatan sosialisasi program yang dilaksanakan secara ekternal maupun internal, mulai dari tingkat propinsi sampai dengan puskesmas baik dalam bentuk metode pertemuan lintas sektor dengan ceramah, maupun berupa instruksi atau persuratan.

Hal ini sesuai dengan yang disampaikan Purwanto and Sulistyastuti 
(2015) bahwa kegiatan penyampaian informasi dalam implementasi kebijakan ini biasa disebut sebagai kegiatan sosialisasi, sosialisasi dapat dilakukan melalui dua cara, yaitu secara langsung dan tidak langsung, dengan tujuan pemberian informasi adalah agar kelompok sasaran memahami kebijakan yang akan diimplementasikan sehingga mereka tidak hanya akan dapat menerima berbagai program yang diinisiasi oleh pemerintah akan tetapi berpartisipasi aktif untuk mewujudkan tujuan kebijakan.

Berdasarkan studi dari Suphanchaimat., dkk (2015) menemukan bahwa beberapa tantangan operasional program dimana faktor komunikasi yang tidak memadai dan panduan layanan yang tidak jelas berkontribusi terhadap ketidakefektifan dalam belanja anggaran dan penyediaan layanan. Tentunya program PISPK ini masih memerlukan lebih banyak sosialisasi agar dapat meningkatkan pemahaman bagi setiap staf yang ada di puskesmas maupun bagi masyarakat yang menerima manfaat dari kegiatan PIS-PK ini.

Faktor sumberdaya berdasarkan hasil penelitian mengenai sumberdaya dibagi berdasarkan alokasi anggaran dan sarana prasarana, dari tiga puskesmas yang diteliti dalam hal ketersediaan instrumen kebijakan dalam hal anggaran, pada tahun 2017 sedikit mengalami kendala karena tidak ada alokasi anggaran yang disiapkan baik dari dinas kesehatan maupun dari puskesmas sedangkan pada tahun 2018 baik dinas maupun puskesmas telah menganggarkan anggaran untuk pelaksanaan program PIS-PK dengan mengacu pada juknis alokasi dan BOK tahun 2018, hanya saja sebahagian informan masih menggunakan dana pribadi untuk menjalankan program karena keterlambatan pencairan dana.

Begitupula dari sarana prasarana hampir semua puskesmas mengeluhkan ketiadaan pinkesga sebagai salah satu instrumen yang harusnya ada pada saat pendataan dan sarana Teknologi Informasi seperti komputer/ handphone android untuk mendukung penginputan belum ada pengadaan khusus begitu juga dengan tensi yang digunakan pada saat mendata masih menggunakan peralatan pribadi dari petugas. Hal ini juga ditemukan dalam penelitian yang dilakukan oleh Laelasari et al. (2017) bahwa yang menjadi kendala dalam pelaksanaan pendataan PIS-PK di puskesmas adalah belum ada peningkatan pengetahuan terutama mengenai IT dan analisis data; belum tersedianya perangkat IT (gadget, program entry yang masih belum pasti) peralatan penunjang seperti IT diperlukan guna mendukung pelayanan kesehatan, diera 
digitalisasi penggunaan internet sebagai sarana komunikasi antar pelayanan kesehatan sudah tidak dapat dihindarkan lagi, kecepatan informasi dibutuhkan agar pengambilan keputusan dapat direncanakan dengan cepat, sehingga penyediaan sumberdaya ini menjadi bagian penting dalam pelaksanaan program. Sebelum menerapkan sistem ini seharusnya dibuat perencanaan yang memadai dan memanfaatkan sumber daya yang dimiliki agar program kegiatan dapat berkelanjutan dengan baik (Kiberu dkk., 2017).

Ketidakselarasan antara sumberdaya yang ada dengan kebutuhan program memiliki risiko yang signifikan terhadap kegagalan implementasi. Faktor-faktor yang menjadi kendala kemampuan informasi dan komunikasi, pendidikan dan keahlian pelaksana serta kemampuan anggaran harus diidentifikasikan dan ditangani sedini mungkin, dalam kajian Ugwuanyi and Chukwuemeka (2013) mengenai hambatan penerapan kebijakan di Nigeria, salah satu dari lima hambatan yang ditemukan adalah permasalahan sumberdaya instansi atau lembaga yang dibebani tanggung jawab melaksanakan kebijakan yang diberikan tidak memiliki sumberdaya yang dibutuhkan baik sumberdaya manusia maupun keuangan untuk penerapan kebijakan yang efektif.
Dalam hal disposisi kesiapan pelaksana adalah hal yang penting dalam mendukung keberhasilan implementasi kebijakan, artinya bahwa sejelas dan sekonsisten apapun peraturan atau kebijakan dilakukan, jika para pelaksananya baik pusat maupun daerah yang terlibat didalam pelaksanaanya kebijakan kurang memahami atau tidak memiliki kesiapan atau kemauan sehingga tidak dapat melakukan kegiatan secara efektif.

Berdasarkan hasil penelitian bahwa sikap seluruh implementor mulai dari tingkat kabupaten sampai dengan puskesmas telah menyatakan kesiapannya untuk mendukung program PIS-PK ini, hal ini dibuktikan meskipun dengan keterbatasan sumberdaya yang ada dalam menjalankan program seperti ketidakadaan pinkesga ataupun dana transportasi kegiatan yang belum cair, mereka tetap bersemangat untuk menjalankan program ini, hal ini dibuktikan dengan capaian pendataan dan pelaksanaan sosialisasi yang telah dilaksanakan.

Penelitian oleh Laelasari et al. (2017) menemukan bahwa pada hasil pengumpulan data kabupaten/kota dengan pendataan lebih dari $50 \%$ Sebagian informan (kepala puskesmas) menyatakan siap melakukan pendataan, yang ditunjukan dengan dibuatnya SK atau surat penugasan khusus 
bagi tenaga yang terlibat. Menurut George $\mathrm{C}$.

Edward III, disposisi atau sikap para pelaksana adalah faktor penting dalam pendekatan mengenai pelaksanaan. Jika pelaksanaan ingin efektif, maka para pelaksana tidak hanya harus memiliki kemampuan untuk melaksanakannya, dimana kualitas dari suatu kebijakan dipengaruhi oleh kualitas atau ciri-ciri dari para aktor pelaksana (Agustino, 2016).

Struktur birokrasi diperlukan untuk mengatur sumber daya atau pelaksana dapat melaksanakan kegiatan dengan kondusif dan terkoordinasi dengan baik. Dalam pengelolaan kebijakan yang kompleks diperlukan struktur birokrasi yang kuat dan dapat mengatur kerjasama orang-orang atau sumber daya di dalamnya secara efektif, dalam program Ini alur birokrasinya bersifat top-down mulai dari kementrian sampai tingkat puskesmas, dari hasil penelitian ditemukan bahwa untuk struktur birokrasi dan jalur koordinasi antara tingkat kabupaten belum berjalan dengan baik tim pengelola kabupaten sampai sejauh ini belum ada struktur yang jelas karena SK belum dikeluarkan oleh dinas kesehatan, kepala dinas kesehatan telah menunjuk bagian perencanaan dan pelayanan sebagai pengelola program ini tapi belum berjalan secara maksimal, sampai saat ini pihak puskesmas belum pernah melakukan koordinasi yang resmi dengan pengelola di dinas kesehatan mengenai capaian program sejauh ini.

$$
\text { Menurut Handoko }
$$
pendelegasian wewenang atau tanggung jawab dari atasan kepada bawahan merupakan suatu proses yang diperlukan agar organisasi dapat berfungsi lebih efisien dan efektif. Delegasi memungkinkan bawahan untuk tumbuh dan berkembang. langkah utama dalam melakukan pendelegasian wewenang atau tanggung jawab adalah penjelasan penugasan, spesifikasikan tentang keleluasaan bawahan, memberikan kesempatan pada bawahan untuk berpartisipasi dan menetapkan kontrol umpan balik. Dengan ini maka bawahan akan menerima pertanggung jawaban untuk hasilhasil yang akan menerima pertanggung jawaban untuk hasil-hasil yang akan diharapkan. Ketua organisasi atau penanggung jawab program dapat mendelegasikan wewenang kepada anggota organisasi lainnya bila dianggap perlu dan bermanfaat untuk pencapaian keberhasilan program.

\section{KESIMPULAN DAN SARAN}

Implementasi Program Indonesia

Sehat dengan Pendekatan Keluarga telah berjalan di semua Puskesmas Kabupaten 
Polewali Mandar sejak tahun 2017, namun belum berjalan dengan maksimal. adapun Faktor yang mendukung implementasi kebijakan adalah Faktor komunikasi, dimana sosialisasi telah dilaksanakan baik dari internal maupun eksternal, Faktor sikap petugas yang menerima program dengan baik dan telah melaksanakan kegiatan pendataan keluarga guna mendukung keberhasilan PISPK, sedangkan Faktor yang menghambat adalah dari Faktor sumberdaya dimana keterbatasan dan keterlambatan pencairan anggaran serta sarana prasarana program yang kurang membuat program kurang berjalan maksimal, sedangkan dari Faktor Struktur Birokrasi, koordinasi berjenjang antar dinas kesehatan dan puskesmas belum berjalan dengan baik, Saran kami, agar dinas kesehatan kabupaten dapat segera membuat struktur organisasi program untuk mempermudah koordinasi, memudahkan proses pencairan anggaran serta mengadakan sarana-prasarana pendukung program.

\section{DAFTAR PUSTAKA}

Agustino, L. (2016). Dasar-Dasar Kebijakan Publik (Edisi Revisi). Bandung: Alfabeta.

Ayuningtyas, D. (2015). Kebijakan Kesehatan: Prinsip dan Praktik. Jakarta: Rajawali Pers.
Direktorat Kesehatan Keluarga Kementerian Kesehatan. (2016) Laporan Tahunan Direktorat Kesehatan Keluarga Tahun 2016. Jakarta.

Handoko, T. H. (2003). Manajemen Edisi 2. Yogyakarta: BPFE.

Peraturan Menteri Kesehatan Republik Indonesia Nomor 39 Tahun 2016 tentang Pedoman Penyelenggaraan Program Indonesia Sehat dengan Pendekatan Keluarga (PIS-PK) (2016).

Laelasari, E., Anwar, A., \& Soerachman, R. (2017). Evaluasi Kesiapan Pelaksanaan Program Indonesia Sehat Dengan Pendekatan Keluarga. Jurnal Ekologi Kesehatan, 16(2), 57-72.

Laksono, A. D., Mubasyiroh, R., Laksmiarti, T., Nurhotimah, E., Suharmiati, \& Sukoco., N. E. (2016). Aksesibilitas Pelayanan Kesehatan di Indonesia. Daerah Istimewa Yogyakarta: PT Kanisius.

Purwanto, E. A., \& Sulistyastuti, D. R. (2015). Implementasi Kebijakan Publik : Konsep dan aplikasinya di Indonesia. Yogyakarta: Penerbit Gava Media.

Rocha, R., \& Soares, R. R. (2010). Evaluating The Impact Of Community-Based Health Interventions: Evidence From Brazil's Family Health Program. Helath Econ, 19, 126-158. doi: 10.1002/hec.1607

Siddharudha Shivalli, J. P. M., K. M. Akshaya, Ghulam Jeelani Qadiri. (2015). Family Centered Approach in Primary Health Care: Experience from an Urban Area of Mangalore, India. The Scientific World Journal. 
Pujosiswanto , 2020

Ugwuanyi, B. I., \& Chukwuemeka, E. E. O. (2013). The Obstacles To Effective Policy Implementation By The Public Bureaucracy In Developing Nations: The Case Of Nigeria. Kuwait Chapter of Arabian Journal of Business and Management Review, 2(7). 